\title{
Mainstreaming of Health Equity in Infectious Disease Control Policy During the COVID-19 Pandemic Era
}

\author{
Hongjo Choi ${ }^{1,2}$, Seong-Yi Kim', Jung-Woo Kim', Yukyung Park³, Myoung-Hee Kim'; \\ Working Group for the People's Report on COVID-19 in Korea* \\ 'People's Health Institute, Seoul, Korea; '2Department of Preventive Medicine, Konyang University College of Medicine, Daejeon, Korea; ${ }^{3}$ Department \\ of Preventive Medicine, Kangwon National University Hospital, Chuncheon, Korea
}

The Korean government's strategy to combat coronavirus disease 2019 (COVID-19) has focused on non-pharmaceutical interventions, such as social distancing and wearing masks, along with testing, tracing, and treatment; overall, its performance has been relatively good compared to that of many other countries heavily affected by COVID-19. However, little attention has been paid to health equity in measures to control the COVID-19 pandemic. The study aimed to examine the unequal impacts of COVID-19 across socioeconomic groups and to suggest potential solutions to tackle these inequalities. The pathways linking social determinants and health could be entry points to tackle the unequal consequences of this public health emergency. It is crucial for infectious disease policy to consider social determinants of health including poor housing, precarious working conditions, disrupted healthcare services, and suspension of social services. Moreover, the high levels of uncertainty and complexity inherent in this public health emergency, as well as the health and socioeconomic inequalities caused by the pandemic, underscore the need for good governance other than top-down measures by the government. We emphasize that a people-centered perspective is a key approach during the pandemic era. Mutual trust between the state and civil society, strong accountability of the government, and civic participation are essential components of cooperative disaster governance.

Key words: Health equity, COVID-19, Infectious disease, Health policy, Right to health

\section{INTRODUCTION}

During the coronavirus disease 2019 (COVID-19) pandemic, many global leaders and celebrities contracted COVID-19. These high-profile cases contributed to the widespread idea

Received: December 3, 2020 Accepted: January 5, 2021

Corresponding author: Myoung-Hee Kim

People's Health Institute, 36 Sadang-ro 13-gil, Dongjak-gu,

Seoul 07004, Korea

E-mail: mhkim@health.re.kr

*A full list of the members of the Working Group for the People's Report on COVID-19 in Korea is provided in the acknowledgements.

This is an Open Access article distributed under the terms of the Creative Commons Attribution Non-Commercial License (https://creativecommons.org/licenses/bync/4.0// which permits unrestricted non-commercial use, distribution, and reproduction in any medium, provided the original work is properly cited. that the virus universally attacks people without any discrimination. This claim is not new, as the contention that "the flu hit the rich and the poor alike" was widely accepted during the Spanish flu epidemic of 1918 [1]. However, the incidence and mortality of Spanish flu were unequally distributed by socioeconomic position. Similar patterns of health inequity have been repeatedly observed for various infectious diseases such as tuberculosis and human immunodeficiency virus [2,3]. Although the differential impact of COVID-19 pandemic on disadvantaged populations has been reported worldwide $[4,5]$, this issue has received relatively little attention from researchers in Korea. A few studies have identified inequalities in the incidence and mortality of COVID-19 across income groups, but the their focus was not to examine the unequal effects of the pandemic $[6,7]$. 
The Korean government's strategy to combat COVID-19 has focused on testing, tracing, and treatment, along with nonpharmaceutical interventions such as social distancing and wearing masks, and its performance has been relatively good compared to that of many other countries heavily affected by COVID-19. However, little attention has been paid to socioeconomic inequalities, and the value of alleviating these inequalities has not been clearly recognized as a way to control the pandemic.

During the early phase of the pandemic, we conducted a study to interpret the pandemic situation from a people-centered perspective. The study team reviewed published and unpublished papers, and interviewed vulnerable populations including homeless people, immigrant workers, the disabled, healthcare workers, and precarious workers. We released a report titled the "People's Report on the COVID-19 Pandemic in South Korea" [8]. This review was conducted to restructure a part of the report with the aims of examining the unequal impacts of COVID-19 across socioeconomic groups and suggesting potential solutions to tackle these inequalities.

\section{Conceptual Framework}

The COVID-19 pandemic could have unequal health and social consequences across socioeconomic groups, both directly [5] and indirectly [9]. Figure 1 depicts a conceptual framework for the direct and indirect impacts of COVID-19, with potential mechanisms linking socioeconomic position and health. The holistic framework spanning from distal determinants to proximate risk factors for health developed by the Commission on Social Determinants of Health [10] presumes that political, economic, and environmental policies could affect various social determinants of health and subsequently, influence health outcomes. These mechanisms could be used to identify entry points for interventions to mitigate the direct impact of COVID-19 on health inequity. For instance, comorbidities affected by social determinants could diminish the function of the immune system and provide a fertile ground for contracting COVID-19 and having a poor prognosis. Social determinants could directly influence COVID-19 infection and its consequences regardless of individuals' comorbidities. Moreover, strong mitigation measures such as lockdowns and closure of workplaces and schools could contribute to unemployment, income loss, mental health deterioration, child abuse, and gender violence [11]. These negative impacts are not equally distributed; instead, they disproportionately accumulate among disadvantaged populations, including precarious workers. Delayed or disrupted healthcare utilization, which is driven by the fact that the public healthcare system is solely committed to dealing with the COVID-19 pandemic, is also a crucial social determinant of health. Based on this conceptual framework, this study examined the extent of our knowledge of the direct and indirect impacts of COVID-19 from empirical studies and elaborated upon the role of social determinants in Korea.

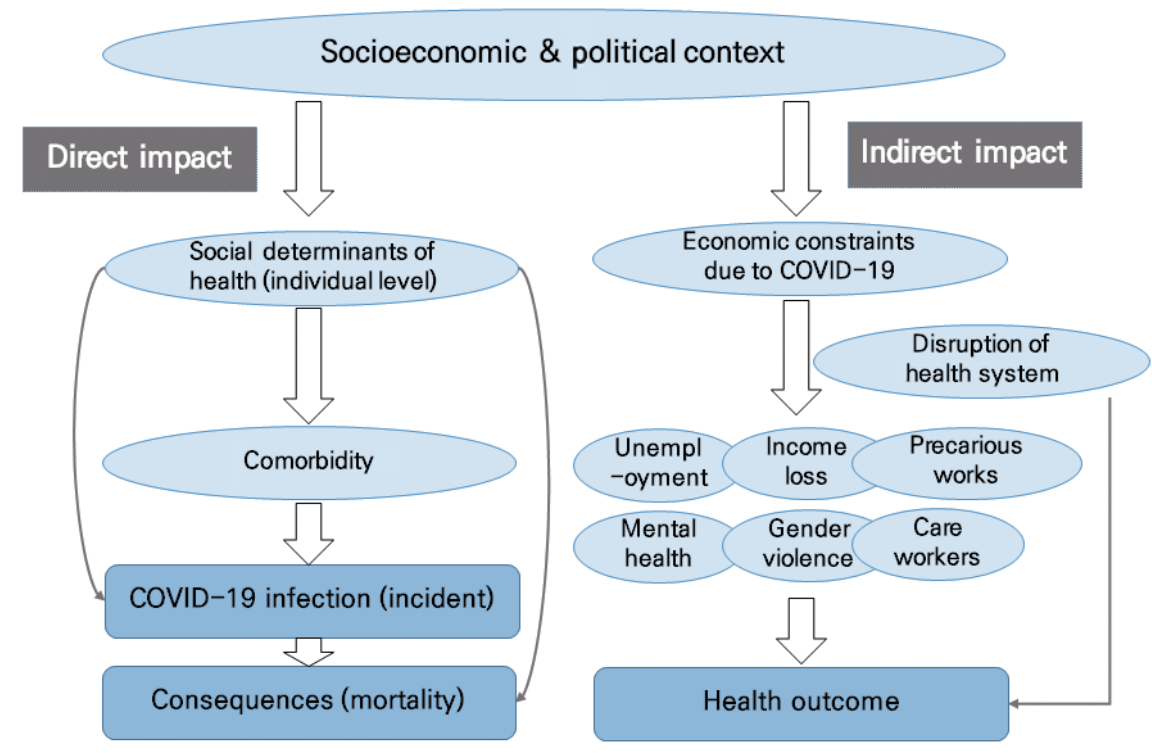

Figure 1. Pathways of health inequities in the coronavirus disease 2019 (COVID-19) era. Modified from: Bambra et al. J Epidemiol Community Health 2020;74(11):964-968 [11]. 


\section{WHAT WE KNOW: EMPIRICAL EVIDENCE IN THE CONTEXT OF KOREA}

Several studies have found associations between income level and COVID-19 morbidity and mortality in Korea. In a cohort of patients with hypertension, COVID-19 incidence was higher in the low-income group than in the higher-income group [7]. An observational study analyzing the data of approximately 9000 COVID-19 patients from the National Health Insurance Service identified higher COVID-19 mortality in the low-income group than in the highest-income group [6]. Other studies have reported that comorbidities had negative effects on COVID-19 mortality $[12,13]$. Based on those findings, although those studies did not aim to identify heath inequities, we would argue that the direct impact of social determinants has been partially verified. Few studies have focused on the indirect impacts of COVID-19 in Korea. One United Kingdom study found higher all-cause mortality among marginalized populations, compared with those in preceding years [10]. Although inequalities in all-cause mortality during the COVID-19 pandemic in Korea have not been verified, a study provided partial evidence for the negative impact of the curtailment of essential healthcare services. Specifically, researchers found that the tuberculosis notification rate in Korea had declined during the COVID-19 pandemic compared to the previous 5 years in Korea [14].

\section{POTENTIAL PATHWAYS TO BE REVIEWED}

The direct impacts of COVID-19 pandemic on health inequity involve an unequal risk of infection and its health consequences. Living conditions are among the most important social determinants. Populations excluded from mainstream society, including migrant workers, the disabled living in facilities, and homeless individuals, have faced being socially distanced and marginalized even before the pandemic, and ironically their condition of being "distanced" was considered as a safeguard against virus transmission. The reality is that their living spaces are very cramped, and they must involuntarily share common spaces such as toilets and kitchens. Accordingly, a single case of infection could bring devastating consequences in the community, as shown in the outbreak in a long-term care hospital in Cheongdo, where 103 patients were infected and 8 patients died of COVID-19 [15]. The building design and methods of patient care facilitated the spread of the virus, and cohort isolation without appropriate protection measures resulted in this disastrous event [16].

Crowded workplaces are another favorable environment for the spread of COVID-19, and a series of outbreaks have occurred in call centers and warehouses. Those workplaces were very crowded and proper distancing between workers was impossible $[17,18]$. Protective measures such as a ventilation system, masks, and hand-washing facilities were limited as well [19]. Moreover, precarious workers are hardly in a position to demand appropriate measures for infection prevention due to the power imbalance between them and their employers [20]. This power relationship is closely related to vulnerable working conditions and employment status, which subsequently impose a double burden on workers [21].

One of the important pathways through which COVID-19 exerts indirect effects on health inequity is disrupted healthcare utilization. Disadvantaged populations such as undocumented immigrants and homeless people usually visit public hospitals, but all public hospitals were designated as COVID-19 treatment centers and minimized their usual medical services. Meanwhile, private hospitals, although they are not-for-profit entities and are mainly funded by the National Health Insurance Services, often refuse to treat patients with mild respiratory symptoms or signs [22].

In addition to medical services, the provision of social services was limited to prevent virus transmission. The central government announced a recommendation to close community centers for welfare services on February 28, 2020, and accordingly, about $99 \%$ of 111101 centers were shut down until April [23]. The disabled were temporarily unable to access rehabilitation services and homeless people had to skip their meals because of the closure of free meal services [24].

By reinforcing the existing social inequity, the negative impacts of the COVID-19 pandemic on health have been aggravated. COVID-19 is literally a "systemic pandemic of inequity" [9].

\section{WHAT WE NEED TO RESPOND TO THE PANDEMIC FAIRLY AND EQUITABLY}

\section{People-centered Perspective}

In recent years, the notion of a "people-centered perspective" has emerged in various fields as a critique of state power, market power, and expert-centeredness. In the public health field, "people-centered" means that care and management are 


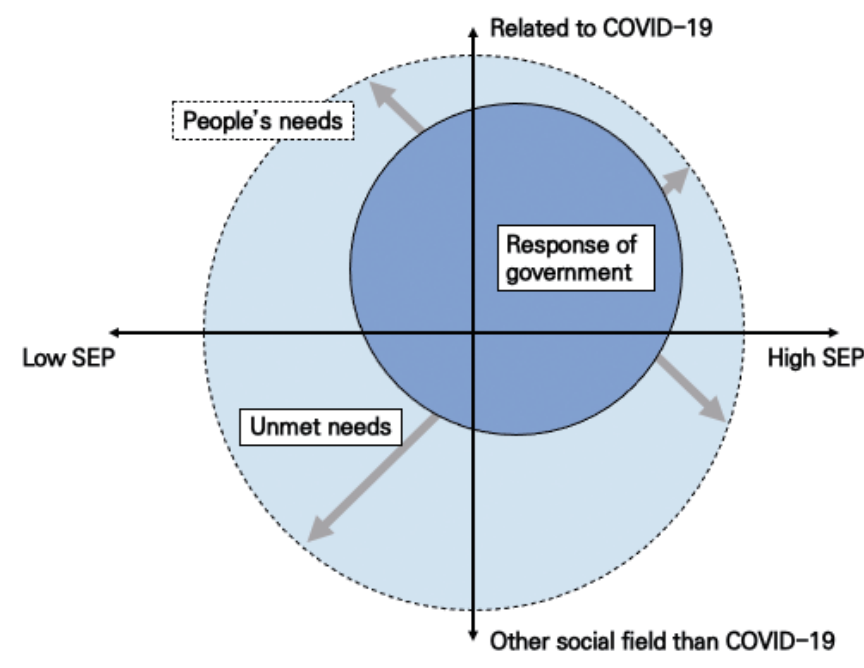

Figure 2. Response of the government from an administrative-centered perspective. COVID-19, coronavirus disease 2019; SEP, socioeconomic position.

organized around the health needs and expectations of people rather than diseases and providers' perspectives $[25,26]$. The response to COVID-19 in Korea was closer to an administrative-centered perspective than a people-centered perspective. Closure of public spaces enabled the public authorities to avoid responsibility for possible outbreaks in the spaces under their control, without considering the suffering and needs of people affected by the abrupt suspension of services. This led to unequal impacts, as shown in Figure 2. For a public health emergency response from a people-centered perspective, we need to ask what people can do, what people want to do in their daily lives, and who people engage in those activities with. We should make efforts to identify people's competencies and provide the necessary support for sustaining their life [27]. Good governance and civic participation are the main strategies to achieve this goal, and a people-centered perspective should be both a principle and an way of approach.

\section{Good Governance and Civic Participation}

The policy measures to respond the COVID-19 pandemic include socioeconomic interventions beyond public health policies. To minimize the human suffering caused by the both the social and health impacts of the pandemic, "democratic publicness" in the multilayered social system is important. This framework can alleviate the harmful effects of the pandemic, by enabling people to participate in the decision-making process and its practices. There is a high-level of uncertainty in public health emergencies such as pandemics, and the government alone cannot manage and control these unprecedented risks. The government and civil society have limited information and knowledge. Most solutions are provisional and are likely to be revised as new scientific evidence is obtained. Accordingly, it is crucial to establish a relationship of mutual trust between the government, experts and citizens. It is for this reason that we have emphasized the need for "cooperative disaster governance" based on collective intelligence from the diverse experiences of different stakeholders [28].

This unprecedented pandemic has allowed the government to restrict the liberty of the citizens to protect them and the wider public from infection. Such measures are indispensable to some extent, but are often followed by unequal distribution of the risk and infringement of human rights. The meaningful participation of civil society in decision-making at various levels is essential to monitor the government and reinforce their accountability to the people more than ever. The economists Bowles and Carlin [29] suggested that the civil society could provide an essential strategy to overcome the pandemic through pursuing public virtue and willingness to cooperate with government, promoting trust in the public health measures recommended by government, and practicing ethical values such as fairness, sustainability, and reciprocity.

To establish cooperative disaster governance during this public health emergency, we would like to suggest the following core components. First, cooperative governance should aim to realize social values including fairness, transparency, and equity. This public health emergency is a form of harm at a society-wide scale, and therefore should be recognized as a common task between the state and civil society.

Second, cooperative governance does not imply shifting accountability from the government to civil society. In most situations, the state is the only polity with the physical power and economic resources to deal with the enormous and complex problems encountered during a disaster [30]. The government should recognize its accountability more as part of cooperative governance.

Third, the government should establish channels to communicate and cooperate with various civil society organizations, and support communities to organize themselves.

Fourth, risk perceptions are important to consider for promoting protective behaviors by individuals, and efforts to encourage appropriate risk perceptions should be made during 
the COVID-19 pandemic, as non-pharmaceutical interventions based on voluntary cooperation of people are the only available measures to combat the spread of COVID-19 [31]. The risk communication of the government should be focused on the following 6 values: "be first," "be right," "be credible," "express empathy," "promote action," and "show respect" [32].

Finally, decentralized governance should be institutionalized to procure public health resources and allow citizens to participate in actions within the local context. The global pandemic has served as an opportunity to recognize the importance of local responses; the risk and damage have not been equally distributed across regions, and communities with fewer resources have been more likely to be hit by the pandemic itself and affected by its consequences.

\section{CONCLUSION}

Based on a review of the existing literature, we constructed a conceptual framework to depict the direct and indirect impacts of COVID-19 on health and social inequalities. The pathways linking social determinants and health could be entry points to tackle the unequal consequences of this public health emergency. Poor housing, precarious working conditions, disruptions of healthcare services, and suspension of social services are relevant examples of social determinants.

The COVID-19 pandemic and responses to the pandemic have resulted in the unequal distribution of risk and burden across regions and social groups. The high-levels of uncertainty and complexity inherent in this public health emergency, as well as the health and socioeconomic inequalities caused by the pandemic, underscore the need for good governance other than top-down measures by the government. Mutual trust between the state and civil society, strong accountability of the government, and civic participation are essential components of cooperative governance.

The COVID-19 pandemic will not be the last public health emergency for the human race. If we learn lessons from the COVID-19 pandemic and engage in preparedness planning based on these lessons, we may be able to respond fairly and equitably to future public health emergencies.

\section{Ethics Statement}

This paper is a special article based on literature review, so it did not need ethical approval.

\section{CONFLICT OF INTEREST}

The authors have no conflicts of interest associated with the material presented in this paper.

\section{FUNDING}

None.

\section{ACKNOWLEDGEMENTS}

A full list of the members of Working group for the People's Report on COVID-19 in South Korea: Sera Kim (Department of Public Health Science, Graduate School, Korea University, Seoul, Korea); Youngsun Kim (Korea Institute of Labor Safety and Health, Seoul, Korea); Jeongwook Kim (People`s Health Institute, Seoul, Korea); Junhewk Kim (Yonsei University, College of Dentistry); Jimin Gim (Incheon Public Agency for Social Service, Incheon, Korea); Jin-Hwan Kim (Graduate School of Public Health, Seoul National University, Seoul, Korea); Myoung-sook (Activist group for human rights 'Baram', Seoul, Korea); Hyojung Son (People`s Health Institute, Seoul, Korea); Youngsil Yang (Health Right Network, Seoul, Korea); Do Yeon Lee (Graduate school of Public Health, Seoul National University, Seoul, Korea); Yeon-Ho Lee (Seoul Center for Integrated Public Health Promotion Program, Seoul, Korea); Sun-Hee Yim (College of Medicine, The Catholic University of Korea, Seoul, Korea); Hyeseung Jeong (Lee, Jeong \& Kim, Seoul, Korea); Eun Kyung Choi (Medical Education Center, Kyungpook National University, School of Medicine, Daegu, Korea); Hyuk-Kyoo Choi (Center for Culture and Society, Seoul, Korea).

\section{AUTHOR CONTRIBUTIONS}

Conceptualization: HC, SYK, JWK, YP, MHK. Data curation: HC, SYK, JWK, YP, MHK. Formal analysis: HC, SYK, JWK, YP. Funding acquisition: None. Methodology: HC, JWK. Visualization: HC, YP. Writing - original: HC, SYK, JWK, YP, MHK. Writiong - review \& edition: HC, SYK, JWK, YP, MHK.

\section{ORCID}

Hongjo Choi https://orcid.org/0000-0001-8853-7061

Seong-Yi Kim https://orcid.org/0000-0002-6045-6080

Jung-Woo Kim https://orcid.org/0000-0002-4234-5598 
Yukyung Park https://orcid.org/0000-0002-5727-8973

Myoung-Hee Kim https://orcid.org/0000-0002-6122-1363

\section{REFERENCES}

1. Sydenstricker E. The incidence of influenza among persons of different economic status during the epidemic of 1918. 1931. Public Health Rep 2006;121 Suppl 1:191-204.

2. Jung-Choi K, Khang YH, Cho HJ. Changes in contribution of causes of death to socioeconomic mortality inequalities in Korean adults. J Prev Med Public Health 2011;44(6):249-259.

3. Blas E, Sivasankara Kurup A. Equity, social determinants and public health; 2010 [cited 2020 Dec 1]. Available from: https:// apps.who.int/iris/handle/10665/44289.

4. Hawkins D. Social determinants of COVID-19 in Massachusetts, United States: an ecological study. J Prev Med Public Health 2020;53(4):220-227.

5. Williams DR, Cooper LA. COVID-19 and health equity-a new kind of "herd immunity". JAMA 2020;323(24):2478-2480.

6. Kim DW, Byeon KH, Kim J, Cho KD, Lee N. The correlation of comorbidities on the mortality in patients with COVID-19: an observational study based on the Korean National Health Insurance big data. J Korean Med Sci 2020;35(26):e243.

7. Kim J, Kim DW, Kim KI, Kim HB, Kim JH, Lee YG, et al. Compliance of antihypertensive medication and risk of coronavirus disease 2019: a cohort study using big data from the Korean National Health Insurance Service. J Korean Med Sci 2020; 35(25):e232.

8. People's Health Institute. The people's report on the COVID-19 in South Korea; 2020 [cited 2020 Nov 30]. Available from: [cited 2020 Nov 30]. Available from: http://health.re.kr/?p=7069 (Korean).

9. Benach J. We must take advantage of this pandemic to make a radical social change: the coronavirus as a global health, inequality, and eco-social problem. Int J Health Serv 2021;51(1): 50-54.

10. Commission on Social Determinants of Health. Closing the gap in a generation: health equity through action on the social determinants of health; 2008 [cited 2020 Dec 1]. Available from: https://www.who.int/social_determinants/final_report/csdh_ finalreport_2008.pdf.

11. Bambra C, Riordan R, Ford J, Matthews F. The COVID-19 pandemic and health inequalities. J Epidemiol Community Health 2020;74(11):964-968.

12. Moon SS, Lee K, Park J, Yun S, Lee YS, Lee DS. Clinical Charac- teristics and mortality predictors of COVID-19 patients hospitalized at nationally-designated treatment hospitals. J Korean Med Sci 2020;35(36):e328.

13. Sung HK, Kim JY, Heo J, Seo H, Jang YS, Kim H, et al. Clinical course and outcomes of 3,060 patients with coronavirus disease 2019 in Korea, January-May 2020. J Korean Med Sci 2020; 35(30):e280.

14. Kwak N, Hwang SS, Yim JJ. Effect of COVID-19 on tuberculosis notification, South Korea. Emerg Infect Dis 2020;26(10):25062508.

15. Korean Society of Infectious Diseases; Korean Society of Pediatric Infectious Diseases; Korean Society of Epidemiology; Korean Society for Antimicrobial Therapy; Korean Society for Healthcare-associated Infection Control and Prevention; Korea Centers for Disease Control and Prevention. Report on the epidemiological features of coronavirus disease 2019 (COVID-19) outbreak in the Republic of Korea from January 19 to March 2, 2020. J Korean Med Sci 202;35(10):e112.

16. Park JY, Chun YK. COVID-19 cluster infection at Cheongdo Daenam Hospital, never ending questions. NewsCham; 2020 Mar 31 [cited 2020 Nov 30]. Available from: http://www.newscham. net $/$ news/view.php?board $=$ news\&category $1=2 \&$ nid $=104726$ (Korean).

17. Park SY, Kim YM, Yi S, Lee S, Na BJ, Kim CB, et al. Coronavirus disease outbreak in call center, South Korea. Emerg Infect Dis 2020;26(8):1666-1670.

18. Jun JH. Another call center hit by COVID-19 infection cluster. Korea Times; 2020 Nov 5 [cited 2020 Nov 30]. Available from: https://www.koreatimes.co.kr/www/nation/2020/11/119_ 298806.html.

19. Lee BR, Yi CY. A worker infected with COVID-19 at Coupang logistics center requests recognition of industrial accident. Kyunghyang Shinmun; 2020 Jul 9 [cited 2020 Nov 30]. Available from: http://english.khan.co.kr/khan_art_view.html?arti $d=202007091853237 \&$ code $=940702 \& w w w=\# c s i d x d c e 607$ 8ad4ea5f984e74be982b0d8a.

20. Kim JH. Coupang's worker angry over company's 'irresponsible' countermeasure. Korea Times; 2020 Jun 10 [cited 2020 Nov 30]. Available from: https://www.koreatimes.co.kr/www/tech/ 2020/08/694_290966.html.

21. Lee J, Kim M. Estimation of the number of working population at high-risk of COVID-19 infection in Korea. Epidemiol Health 2020;42:e2020051.

22. Song SY. Migrant workers sacrifice outdoor life to avoid cluster infections. Korea Biomedical Review; 2020 Oct 21 [cited 2020 
Nov 30]. Available from: http://www.koreabiomed.com/news/ articleView.html?idxno $=9439$.

23. Ha K. All-stop welfare services for the elderly, including suspension of community care and restrictions on new hospitalization at nursing hospitals because of COVID-19. Medigate News; 2020 Apr 14 [cited 2020 Nov 30]. Available from: https:// medigatenews.com/news/1635935177 (Korean).

24. Ser MJ. People with disabilities left behind by Korea's Covid response. Korea JoongAng Daily; 2020 Nov 23 [cited 2020 Nov 30]. Available from: https://koreajoongangdaily.joins.com/ 2020/11/23/national/socialAffairs/Covie19-disablities-KoreanParents-Network-for-People-with-Disabilities/20201123161900437.html.

25. World Health Organization. People-centred health care: a policy framework; 2007 [cited 2020 Dec 1]. Available from: https:// iris.wpro.who.int/bitstream/handle/10665.1/5420/9789290613176_eng.pdf.

26. World Health Organization. WHO global strategy on peoplecentred and integrated health services: interim report; 2015 [cited 2020 Dec 1]. Available from: https://www.who.int/servicedeliverysafety/areas/people-centred-care/global-strate- gy/en/.

27. Villeneuve M, Sterman J, Llewellyn GL. Person-centred emergency preparedness: a process tool and framework for enabling disaster preparedness with people with chronic health conditions and disability; 2006 [cited 2020 Nov 30]. Available from: https://www.sydney.edu.au/health-sciences/cdrp/projects/UOS_PrepareNSW_user_guide_FINAL_v2.pdf.

28. Jasanoff $S$. Citizens at risk: cultures of modernity in the US and EU. Sci Cult 2002;11(3):363-380.

29. Bowles S, Carlin W. The coming battle for the COVID-19 narrative. VoxEU; 2020 Apr 10 [cited 2020 Nov 30]. Available from: https://voxeu.org/article/coming-battle-covid-19-narrative.

30. Giroux HA. Reading Hurricane Katrina: race, class, and the biopolitics of disposability. Coll Lit 2006;33(3):171-196.

31. Collins A, Florin MV, Renn O. COVID-19 risk governance: drivers, responses and lessons to be learned. J Risk Res 2020;23(7-8): 1073-1082.

32. Reynolds B. Crisis \& emergency risk communication: what the public needs when risks are uncertain; 2016 [cited $2020 \mathrm{Nov}$ 30]. Available from: https://www.cdc.gov/zika/zap/pdfs/Crisis-and-Emergency-Risk-Communication.pdf. 